\title{
The Rise of the East: What Does it Mean for Development Studies?
}

\author{
Hubert Schmitz
}

\begin{abstract}
1 Introduction
The world has changed dramatically over the last 30 years. The Second World has virtually disappeared. The Third World has gone in different directions, with some areas declining and other areas experiencing the fastest sustained economic growth in history. And the First World, so jubilant over the demise of the Second World (the fall of the Berlin Wall and disintegration of the Soviet bloc), is now struggling to maintain its high living standards against competition from the formerly poor countries in the East. The speed of industrialisation in China and other Asian countries is breathtaking. They are not just catching up, they have begun to drive the changes in the rest of the world. This article is particularly concerned with this rise of the East and asks what it means for development studies. Does development studies have a place in this new world? Which strands have something to offer, which strands should be discarded? What challenges need to be taken on for development studies to thrive and avoid becoming irrelevant?
\end{abstract}

The article starts by highlighting the rise of the East, focusing in particular on the growth and transformation of China. It then distinguishes between four broad strands of development studies and shows how each strand is affected by the rise of the East. It concludes by discussing the need for a new vocabulary to make sense of the new world and - closely related to this - the need to break through a psychological barrier: analysing how the former 'periphery' is now driving change in the 'centre'.

Because the issues raised are large and so as to keep the sweep, I have refrained from including literature references. In order to provoke discussion, I have also refrained from qualifying the main propositions with footnotes.

\section{The rise of the East}

It is only 30 years ago that the 'great proletarian cultural revolution' came to an end. The revolution made China materially and culturally poor but egalitarian in a way the world had not seen before. Today the country is booming materially and culturally, but it has also become a very unequal society. What happened in China over this period is unbelievable: 30 years of economic growth at a yearly average of 9 per cent. Without exaggeration, Newsweek calls it 'the most successful case of economic development in human history' (6 March 2006).

Full explanations of this growth and transformation have yet to emerge but the key factors seem clear:

- Internally it was the unlikely combination of the ideas of Adam Smith and the Chinese Communist Party. Adam Smith's central message was that economic development depends on the depth of the division of labour which in turn depends on the size of the market. China's internal market is big and it is growing fast with the removal of internal barriers and rising incomes. The depth of specialisation within China is little recognised but it is becoming visible to any visitor to industrial clusters and the emerging 'commodity markets'. The contribution of the Chinese Communist Party lies in governing this market and controlling the transition to a new system. The Party experimented with transitional institutions, which made it possible to move in stages from a society without private means of production to a capitalist society, and which made it possible to move gradually from a centrally planned to a market economy.

- Externally, the key explanatory factor lies in what one can call 'China plus'. The country's rapid success in global markets cannot be explained merely by 
reference to internal factors. One needs to consider China plus key neighbours; China plus Hong Kong and China plus multinational companies. To explain each in turn: first, the equipment and complicated components for many products 'made in China' come from neighbouring countries (in particular, Korea, Taiwan and Japan). Second, China's strength in transforming these inputs into final products is formidable but not sufficient; it was Hong Kong that provided the trade networks and logistics to link Chinese factories with their foreign customers. Third, China is able to move rapidly into producing more sophisticated products (in particular electronics) because multinational companies have established their factories - and in some cases also research and development (R\&D) departments - in the country.

From a developmental vieupoint, China provides a fascinating case study of a country that was poor until relatively recently but is now catching up with the advanced countries very fast indeed. The speed and manner of this catching up is itself a very interesting topic, central to the development debate, and is one of the reasons why China has attracted much attention internationally. The main reason, however, for the global attention is that China's rise has major external repercussions. China and its neighbours have become the drivers of global change. At IDS, it has led us to open a new line of research on what we are calling the 'Asian Drivers of Development'. We are trying to understand the enormous opportunities that arise for some but also the big threats confronted by others.

The positive and negative external effects are significant because three things come together: China's size, fast growth and openness. The first two are clear, the third less so. Trade in goods and services (imports plus exports) amounts to around 70 per cent of gross domestic product (GDP), compared with 25-30 per cent in the cases of the USA, Japan or the European Union. China's economic growth has required huge increases in imports and resulted in huge increases in exports This combination of large size, rapid growth and openness is historically unprecedented.

The resulting effects are felt throughout the world Countries in Latin America, Africa and the rest of Asia feel the difference - as do the advanced countries of North America and Western Europe.
We have reached a new stage in the development of the global economy. The former periphery has become the driver of change in the (former?) centre.

Those tempted to rejoice might want to hold back with their celebration. Enormous new problems have emerged, both internal and external to China. Starting with the external: feeding the dragon requires natural resources, which China lacks. International resource wars loom over water and fuel. The internal problems are many, for example 16 of the 20 most air-polluted cities in the world are in China; inequality is increasing rapidly within cities and between regions; massive bad debts highlight the danger of financial instability. In short, there are doubts about the economic and political sustainability of further growth, but so far, there is little sign of a slow-down.

My own impression is that reference to the herd instinct is essential to help explain the current situation. Most Chinese investors (public and private) seem to believe that fast growth will continue; foreign investors (large and small) believe that China is the place to be, and the government matches this enthusiasm with massive infrastructure investment. So with one reinforcing the other, continued fast growth becomes a self-fulfilling prophecy. But there is no inevitability in this process. The Chinese government has the financial and political power to intervene. Over the last 30 years, it has used this power in remarkably shrewd ways - experimenting and finding unorthodox solutions in the process.

Whatever scenario one believes in for China and East Asia, there is little doubt that we have entered a new chapter in world history. But those taking the long view might say that history is merely getting back on track - with Asia resuming its superior and dominant place in the world. In contrast, this article is comparatively short term, stretching back over the last 30 years - or at the most 50 or so years when development studies began.

\section{What is 'development studies'?}

What does the rise of the East, in particular China, mean for development studies? This is the question driving this article. Answering this question requires defining what 'development studies' is. This is not an easy task. There is no agreed definition and controversy is inevitable if one tries to provide one. I adopt here a pragmatic definition which comes 
from observing what development studies institutes (e.g. members of the UK's Development Studies Association) actually do. They:

- study economies, societies, polities in Africa, Latin America and Asia

- consider OECD countries only to the extent that they have an influence on or serve as reference points for African, Latin American and Asian countries

- are (or strive to be) interdisciplinary and multimethod in their approach.

This descriptive definition has its problems. It gives the impression that development studies is a branch of Area Studies with specialists in, for example East Africa or South Asia - on a par with specialists in, for instance, North America or Scandinavia. No doubt country- or region-specific expertise is considered important but most development studies researchers would claim that they have something more fundamental in common:

- the need for analytical frameworks and concepts which capture the different stages, structures and attitudes in Africa, Latin America and Asia (different from those found in OECD countries)

- the concern to understand poverty and inequality, analyse its causes and show ways of improving people's life chances (which are often much worse than those found in OECD countries).

Whichever way one defines development studies, any detailed discussion will quickly find the need to distinguish between different strands. Again there are different ways of identifying strands, none of them right or wrong, but more or less useful depending on the purpose of the exercise. Since this article is particularly concerned with the rise of the East and its implications for development studies, it seems important to pay attention to the strands which (continue to) analyse reality through the Western lens and those which regard Western dominance as the key obstacle for progress. But two other strands of development studies will also be examined. I will call them 'find your own way' and 'putting the poor first'. These four strands do not cover all work carried out under the rubric of development, but they capture major lines of work that have been carried out across the disciplines. I have deliberately kept away from disciplinary discussion. If there is any pride left in belonging to development studies, it resides in being able to observe strengths and weaknesses across the disciplines.

\section{4 'West is best' or 'the overdue burial'}

The first strand of development studies to be examined here is one which has been influential since the 1950s and continues to be so up to this day: adopting the Western lens. I refer here to those studies which analyse, interpret and measure by using a Western reference point. Often this reference point is an idealised version of Western practice: the achievement society, the market economy, parliamentary democracy, the innovation system. Typically, these studies ask in which respect does reality in, for example Bangladesh, differ from a model defined elsewhere (usually in the West); why does the reality not live up to this model? What needs to be done to close the gap?

Such questions pervade all disciplines. In sociology, the Western lens was particularly powerful because of the strong influence of modernisation theory.

Development was seen by most modernisation theorists as the evolution from traditional to modern society. Progress could be assessed by indicators of modernity, derived from the experience of the most advanced modern society: the USA. Most contemporary sociologists would dissociate themselves from such thinking, but the practice of adopting the idealised Western lens remains surprisingly common in many lines of research and policymaking:

\section{- Political science and the push for}

democratisation. Western-style democracy is considered so superior that it is thought legitimate to introduce it by force. Little consideration is given to other forms of participation which might look second best but turn out to be more meaningful to local people and give them the chance to find their own 'voice'.

- Economics and the investment climate. The rediscovery of the importance of economic growth has led to concern with improving the climate for investment. Particular importance is given to the institutional infrastructure (legally enforceable property rights and contracts). The concern with institutions seems right but using models derived from the West provides few 
insights for moving forward in countries where such institutions are absent.

\section{- Innovation studies and the search for systemic}

gains. Participating in the global economy seems essential for improving earning opportunities but how to escape the 'race to the bottom'? Competing by innovating is seen as part of the answer but does the innovation system approach (derived originally from Scandinavian experiences) provide a fruitful analytical and practical way forward? Probably not

Many other examples could be given. Unfortunately, they are not limited to academia. They seem even more common in advisory and consultancy work. Overwhelmed by the complexity of the real world, the German consultant often retreats to what he knows best and derives his recommendations by comparing Central Java with Baden-Wuerttemberg. Japanese consultants seem no better. On the contrary, much of their work consists of lamenting that the developing regions are not like Japan and then making recommendations based on the Japanese experience. In some form or other they repeat the mistaken choice of the modernisation theorists: adopt the best practice of the most advanced region or remain underdeveloped.

I am not arguing here against learning from success. I have emphasised that the idea of 'West is best' (or 'Japanese is best') continues to be prominent. This seems problematic for two reasons. Transplanting ideas and practices without due consideration to differences in context rarely works. This is old hat but deserves to be repeated time and again. The second reason is new and brings us back to the central concern of this article. The legitimacy of adopting the Western lens always rested on the superior performance of the Western economies and societies. This superiority is increasingly questionable. China's growth record over the last 30 years is superior to anything Western nations have ever achieved in their long history. China's ability to manage the transition from a materially impoverished, centrally planned economy to an efficient state-governed market economy is superior to that of the obvious comparator: the Soviet Union. Even though the Soviet Union started at a higher level, and even though (or because) it adopted many ideas recommended by Western advisers, the ex-Soviet republics are being overtaken by China on many fronts.
The key point of this section is that the 'West is best' idea, which has long been suspect, has now lost its last bit of legitimacy. For a long time, this way of analysing and advising derived its justification from the superiority of the Western models and practices. Now that the East is out-competing the West and demonstrating more effective ways forward, using the Western model as a reference point - or the model to live up to - is hard to justify. The burial is overdue.

\section{The West undermines}

The previous section discussed - and dismissed - the influential body of literature which explicitly or implicitly sees development as progress towards idealised Western models. In the conventional political spectrum, this can be seen as literature leaning to the right. In contrast, much of the literature leaning to the left sees development as a process which has been disrupted, undermined or stifled by the West. This includes the classical theories of imperialism, which precede development studies, neo-Marxist theory of underdevelopment, dependency theory, world systems theory, and more recently, some of the anti-globalisation work, for example John Pilger's 2001 programme for ITV, The New Rulers of the World. In spite of differences between them, there is a common core: they regard the interaction with the West as the main obstacle to development

What does the rise of the East tell us about this body of work? If one is restricted to a short answer, one has little choice but to dismiss it as overtaken by events. China trades intensively with the West (and everybody else), no other country has received more foreign direct investment from the West, no other country absorbs Western technology and design more enthusiastically, no other country sends more students to Western universities. China's fast growth would not have been possible without integrating deeply into a global economy dominated by the West. Bill Warren the British Marxist who in the late 1970s and early 1980s so severely criticised his colleagues on the left has won the argument: capitalism is fulfilling its historical mission in the developing world. More than that, in East Asia it has been so successful that it is now driving the change in the West.

A more detailed answer would be useful here:

- The writers in the imperialism/dependency/antiglobalisation strand are right to draw attention to 
the relationship with the West as important, but wrong to assume that the relationship is always negative. The outcome depends on the circumstances. For example, global value chain analysis suggests that the upgrading opportunities of local producers vary with the way the chains are organised. In the case of foreign direct investment, the outcome for national development depends on the terms which the state has been able to negotiate. The East Asian experience shows that national policy helps to be selective with regard to foreign direct investment and then harness the muscle of transnational companies to national development.

- Some of this strand recognises that the outcome depends on the interaction between external and internal forces but propose that the outcome is negative for the majority of the population. This proposition turns out to be right in many instances in Latin America but much less so for East Asia, giving rise to a host of new research questions for which we do not seem to have convincing answers: why is it that enterprises, local government and central government show so much more strategic intent in East Asia?

- While it is right to draw attention to the importance of external forces, the new external forces come increasingly from the East rather than the West. This is why IDS has initiated the Asian Drivers programme. China in particular is driving global changes in:

(a) the quantity and direction of trade (resulting in major changes in relative prices)

(b) the way production and trade are organised (resulting in a shift in locus of coordination of global value chains)

(c) the location of innovation activities (prompting a shift in the global knowledge divide)

(d) global governance (leading to a new unstable multipolarity).

None of this is to suggest that these changes driven by the East produce better developmental outcomes. The outcomes are likely to vary a great deal.

- Couching the change as being Western- or Eastern-driven has its problems. In some sectors, the success of China is due to Western companies' massive investment in factories, supplier development, research facilities, and managerial and technical staff in China. In other sectors, East Asian companies have substantial investment in the West. And there are sectors in which new multinational companies originating from South Africa, Mexico, Brazil, India or Russia are challenging old and new leaders from the West and East. The corporate world has become truly transnational. Understanding this new corporate world is not easy, but critical for a revitalised development studies.

- The idea that these transnationals will now rule the world is also unhelpful. In many sectors, there has been a major change:

(a) from transnational conglomerates prioritising control

(b) to rapidly changing alliances of companies which prioritise core competence and strategic flexibility.

In many sectors, an organisational decomposition has occurred, not just in production processes but also in marketing and innovation processes. The muchlamented decline in state powers has its parallel in fragmenting corporate power. The world is much less predictable and more exciting than most of us would have expected a few years ago.

\section{Find your own way}

There is another strand of development studies which not only survives but is boosted by the rise of the East. I call it 'finding your own way'. Like the other strands discussed before, it can be detected among writers from several disciplines. 'Find your own way' has been advocated by many, but as a research perspective, it has been practised surprisingly little. It certainly requires an open-mindedness which the two previously discussed strands do not allow.

Its most explicit author was the historian Alexander Gerschenkron. In his book Economic Backwardness in Historical Perspective (1962) he argued that latecomers have to plot their own distinctive path of development. Repeating what others have tried before is rarely possible because each country has its own specific internal conditions and because the rise of the early developer changes the external conditions for the latecomer. Analysis of early industrialisation in continental Europe led Gerschenkron to this conclusion. Ron Dore came to the same conclusion in his analysis of Japan: the country succeeded by not simply emulating the 
West. Non-blinkered analysis of the more recent East Asian experience takes us in the same direction.

The key feature of China's development strategy and that of other East Asian countries is that they did not follow models from elsewhere. In Institutions and Economic Growth, Stephan Haggard (2004) emphasised how East Asia succeeded through a long process of 'transition' that was highly experimental in nature. Similarly, Mike Hobday, in a 2003 review of Asian industrial development, concludes that it is diversity rather than uniformity in the institutional arrangements and development policy that characterises the innovation experience of the Asian Tigers.

The importance of step-by-step experimentation comes out most strongly in the Chinese experience of the last three decades. Yingyi Quian shows this convincingly in his article 'How Reform Worked in China' (2003). 'Transitional institutions' rather than 'best practice institutions' were the key. He stresses that the adopted institutions need to take account of the conditions at each stage of the reform process. In China, a market was created through a dual-track approach to liberalisation, enterprises were created through the non-conventional ownership of township-village enterprises, and government was reformed through a particular type of fiscal federalism. These institutional innovations worked for a while and then had to be replaced. Not all of them succeeded but there was a common thread to those that did: 'pragmatic innovation' and aligning the interests of the newly enabled decentralised actors with those of the reformers in central government.

By implication, this strand of development studies, which stresses the need to find one's own way forward, also warns us against seeking to replicate elsewhere what seems to have worked in East Asia. Each country needs to find its own way forward, based on understanding its own strengths and weaknesses and based on understanding the new external context which has been influenced in such a major way by the Asian Tigers and China.

In principle, proponents of this line of development studies should be able to push at open doors. Economics, the dominant discipline in development studies, has finally taken an 'institutional turn', recognising that institutions need more attention in research and advice. In practice, however, this has not led to greater space for context-specific solutions. As stressed by Peter Evans (2004), the attention given to getting the institutions right has led to 'institutional monocropping', advocating the same way forward in vastly different circumstances.

One of the main reasons seems to lie in the internal organisational dynamics of donor agencies. $A$ large part of development research and advice is funded by donor agencies that operate in many countries. The agencies seek internal coherence around particular aims and approaches; they seek to disburse funds for activities which can be shown to promote these aims and use these approaches. There is thus a conflict between respecting diversity and the priorities of recipients on the one hand, and the agency's internal aims and pressures on the other. Because of the need to disburse funds against deadlines, the scope for letting poor countries find their own way in their own time is constrained, particularly in aid-dependent countries. It remains to be seen whether the change to budget support will make a significant difference.

\section{Putting the poor first}

Some of the finest achievements of development studies lie in the analysis of employment, inequality and poverty in Africa, Asia and Latin America. These issues were put on the agenda of both the academic and policy debate by the three International Labour Organization Missions to Colombia, Sri Lanka and Kenya in the early 1970s. Ever since, development studies has been concerned with 'redistribution from growth' and with tracing the implications of policies or projects for poor people.

IDS is closely associated with this. When Dudley Seers asked in his 1972 book 'What we are trying to measure?', he brought out the importance of going beyond growth and measuring the implications for inequality and poverty. Today we have a sophisticated human development index (to which Richard Jolly - a former IDS Director - contributed so much) and we have a new participatory methodology for observing changes through the eyes of the poor (pioneered at IDS by Robert Chambers and the Participation Group). This is a proud legacy, which has led to reams of in-depth poverty analysis and has been very influential in the policy debate worldwide.

For many, this analysis of the poor has become the trademark of development studies. The mission is to focus on the poor and on the poorest countries. While filling a vacuum and reflecting strongly held values of 
researchers and practitioners, it has also become a problem. Targeting the poorest directly and immediately is often given priority in discussions of research design and funding. This leads to development studies being reduced to studying the dependent variable. I am not implying here that the poor are passive: there are impressive stories of the poor organising to defend their rights, as shown by the selfemployed women's association in India, the street traders' union in South Africa, or the landless rural workers' movement in Brazil. The point I am trying to make is that where development studies confines itself to the study of the poor, it runs the risk of giving up on understanding and influencing the forces, which bring about the big changes and differentials in wealth and poverty. This is not a straw man: some researchers have willingly cut themselves off from the big picture, others have failed to obtain funding because they did not deal with the poor directly.

How does all this relate to the rise of the East? If development studies defines itself as the study of the poor and of the poorest countries, then studying the rise of the East is not a central concern.

Development studies would perhaps contribute to analysing poverty within East Asia, but would concentrate on the poorer countries in the rest of Asia, Latin America and in particular Africa. Many aid agencies have gone along this route. Should development studies as well? Should it concentrate on the 'rump' of the developing world?

In my view, this would be a grave mistake. It fails to recognise that China and the East Asian production system have become drivers of change worldwide, including Latin America, Africa and the rest of Asia. What is at stake is whether development studies is concerned with the dynamics that drive this change. Of course, what happens in the rest of the world is not only determined by the East, but this is where the main changes come from. And the effects are not just felt in Africa, Latin America and Asia, they are felt also, or perhaps even more so, in North America, Western Europe and Japan. It is a true revolution: what used to be part of the 'periphery' is now driving changes in the 'centre'. Perhaps development studies should put this reversal on its research agenda. This would show that it has - at last - freed itself from its post-colonial origins.

Development studies is certainly well equipped to take on this new challenge. Unlike most other bodies of work it has a tradition of interdisciplinary analysis, of combining different methods and drawing on the tools developed by other disciplines.

\section{Finding a new language}

As shown in the course of this brief article, the rise of the East poses major challenges to development studies. I have suggested that one strand should be discarded, two need to reposition themselves and only one strand comes out strongly. No doubt, some of the arguments which led to these conclusions are controversial, but hopefully there is less controversy on what I would call the two minimum requirements for moving forward:

- more analytical space for detecting the 'solutions' which come up from below, and

- capturing the global changes which produce wealth and poverty.

The latter requires more than international studies, it necessitates enquiry along the global-local axis.

For development studies to reinvent itself and be at the forefront of new analysis, rather than a relic from the past, it needs to confront a number of further challenges. These challenges arise not just from the rise of the East but also from changes elsewhere. I will merely raise them here, without being able to go into detail, let alone offer solutions.

Current analysis and communication is hampered by poor language. The most frequently used categories - 'developed/developing countries' or 'North/South' do not help us to understand the new world. Over the last 30 years, the former Third World has become so heterogeneous that the use of current categories becomes an obstacle. Brazil and Tanzania have very little in common. China and Sri Lanka similarly. The terms 'newly industrialised countries' and 'least-developed countries' are an improvement, but still not sufficient.

The most grotesque category is that of 'industrialised' countries for the countries of the OECD (given that de-industrialisation has been one of their main characteristics in recent years). In English, this has become less common but not yet in other languages, for example in German, 'Industrieländer' is the most frequently used term. 
Creating a new language which is universally acceptable and has measurable categories will be difficult. A strong candidate is a typology of countries according to sources of state revenue. Such typology would help to bring about an overdue shift to more political analysis. At IDS Mick Moore has shown that state revenue based on taxation (as opposed to foreign aid or export of abundant raw materials) has a major bearing on the likelihood of state formation and effective government. There now seems a case for going one step further and using this line of work on taxation for a categorisation of countries. In discussing this and other candidates, some might worry about a proliferation of terms used concurrently, but this is unlikely to do more damage than continuing with the current language for distinguishing between (groups of) countries.

The problem of course is that there are enormous country-internal differences. Osvaldo Sunkel captured this very well in a 1973 article 'Transnational Integration and National Disintegration'. His central concern was to show the connection between, on the one hand, the economic and cultural integration across countries and, on the other hand, the economic and cultural disintegration within countries. This is precisely what happened in Latin America at the time. And is precisely what has happened in East Asia since then. The difference is that the transnational integration has been much deeper and wider in East Asia and the drivers of the process come increasingly from within the region. Why is it that Sunkel's combined analysis of transnational integration and national disintegration has not entered the mainstream of development studies and produced measurable categories to understand this process more deeply and comparatively? Perhaps the original article was too close to dependency analysis and its pessimistic conclusions.

\section{Acknowledgement}

I am grateful to John Humphrey, Mick Moore and Laura Turquet for helpful comments on the first draft of this article.
The transnational integration keeps reproducing itself and the resulting process of inclusion and exclusion changes the world in a fascinating and outrageous way. Understanding this world requires a language which revolves around connectivity or the lack of it. Such language exists for example in global value chain analysis and in social network analysis, but it needs to be brought into the centre of the new development studies. The challenge is to understand:

- the business and professional networks that make transnational integration work

- the disconnects and lock-outs that lead to misery and injustice, often across national borders

- the new and invisible transnational networks that terrorise the world

- the policy networks that need to be developed along the local-global axis.

This is not to suggest that we abandon a concern with the national or local state. What seems needed is a shift in paradigm about what the state needs to do. The critical capacity of the future state is the management of relationships. Managing relationships is not an end in itself but is critical for securing peace, integrating different cultures, accelerating private investment, delivering services to the poor and many other state functions. Once the management of relationships is at the centre of new analytical and practical work, it becomes more likely that we will escape futile linear ideas of policymaking and find a framework for dealing with the proliferation of actors that have an influence on policy. 